\title{
Seronegative spondarthritis associated with Takayasu's arteritis
}

\author{
M MAGARO', L ALTOMONTE, L MIRONE, A ZOLI, AND G CORVINO \\ From the Divisione di Reumatologia, Istituto di Clinica Medica, Universita' Cattolica del Sacro Cuore, Rome, \\ Italy
}

SUMMARY A young woman presented with an aortic arch syndrome a few years after the onset of ankylosing spondylitis. Tissue typing showed HLA-B27. The possibility of an association between ankylosing spondylitis and Takayasu's arteritis is suggested.

Key words: ankylosing spondylitis.

Ankylosing spondylitis (AS) is a relatively common disease with an overall incidence in whites of $1-2 \%$ and a male/female preponderance of $2: 1 .^{1}$ The dominant lesion is an idiopathic, progressive, inflammatory arthritis of the spinal and sacroiliac joints, and approximately $88 \%$ of the patients are HLA-B27 positive. ${ }^{23}$ Uveitis, prostatitis, pulmonary fibrosis, and cardiovascular lesions, such as conduction defects, ${ }^{4}$ transmural aortitis with aortic incompetence, and slight aortic widening, ${ }^{56}$ are also seen in AS. It is rare, however, to find a patient with AS who presents with a true aortic arch syndrome.

When we reviewed the published work we found only seven cases describing the association of an aortic arch syndrome (Takayasu's arteritis (TA)) with AS. ${ }^{7-10}$ We report a case of a young woman affected by AS associated with TA.

\section{Case report}

A 32 year old woman was first referred to us in November 1986 complaining of low back pain, which had started 15 years previously immediately after the birth of her first child. The pain had initially been present for about 30 days, then after two months without pain there was a second flare up, which initiated a stage of continual discomfort punctuated by periods of increased intensity. During

Accepted for publication 9 December 1987.

Correspondence to Professor Magaro' Mario, Pol A Gemelli, Largo Vito, 8, 00168 Rome, Italy. the next five years the whole spinal range of movements became restricted and the patient showed progressive arthritis of the hips, knees, ankles, wrists, and some small joints of the hands. When the pain was severe the patient was forced to stay in bed, but the pain was not significantly relieved by bed rest. At age 23 the patient began to complain of an intermittent, spontaneously decreasing hyperpyrexia $\left(38.5^{\circ} \mathrm{C}\right)$ and frequent headaches. At that time she first noted the absence of pulsation in both radial arteries. Blood pressure was unrecordable at the upper arms, but high values were recorded at the lower extremities $(180 / 120 \mathrm{mmHg})$. As a result the patient was admitted to hospital five times before we saw her in our rheumatology department.

At admission the patient presented with slight thoracic and cervical kyphosis, loss of lumbar lordosis, and was unable to walk without assistance. Spinal mobility was symmetrically decreased and chest expansion restricted $(<2.5 \mathrm{~cm}$ at the nipple level). Signs of inflammation were present in her wrists, small joints of the hands, knees, and ankles. Hip movements were restricted. Both the upper extremity pulses were unrecordable. All arterial leg pulses were present. No heart murmur was heard.

A pelvic $x$ ray showed evidence of bilateral periarticular sclerosis of the sacroiliac joints with erosive changes at the edges of the right sacroiliac joint (Fig. 1). Scintigraphic examination showed an increased uptake of radionucleotide in both the 
sacroiliac joints, in the lumbar and thoracic spine, and in the right hip. An aortogram demonstrated an occlusion of both the subclavian arteries beyond the origin of the vertebral arteries (Fig. 2); there was also an irregularity of the lumen of the left renal artery; the abdominal aorta was normal. The temporal artery biopsy was negative. The electro- cardiogram and the echocardiogram were normal; i 닦 particular the latter showed no aortic valve or aortie wall abnormalities. The erythrocyte sedimentatio $\$ P$ rate was $86 \mathrm{~mm} / 1$ st hour, the haemoglobin conceno tration $89 \mathrm{~g} / \mathrm{l}$, white blood cell count $9 \times 10^{9} / 10$ platelet count $500 \times 10^{9} / 1$, and gammaglobulins werê $25 \%$. Antinuclear antibodies and rheumatoid facto

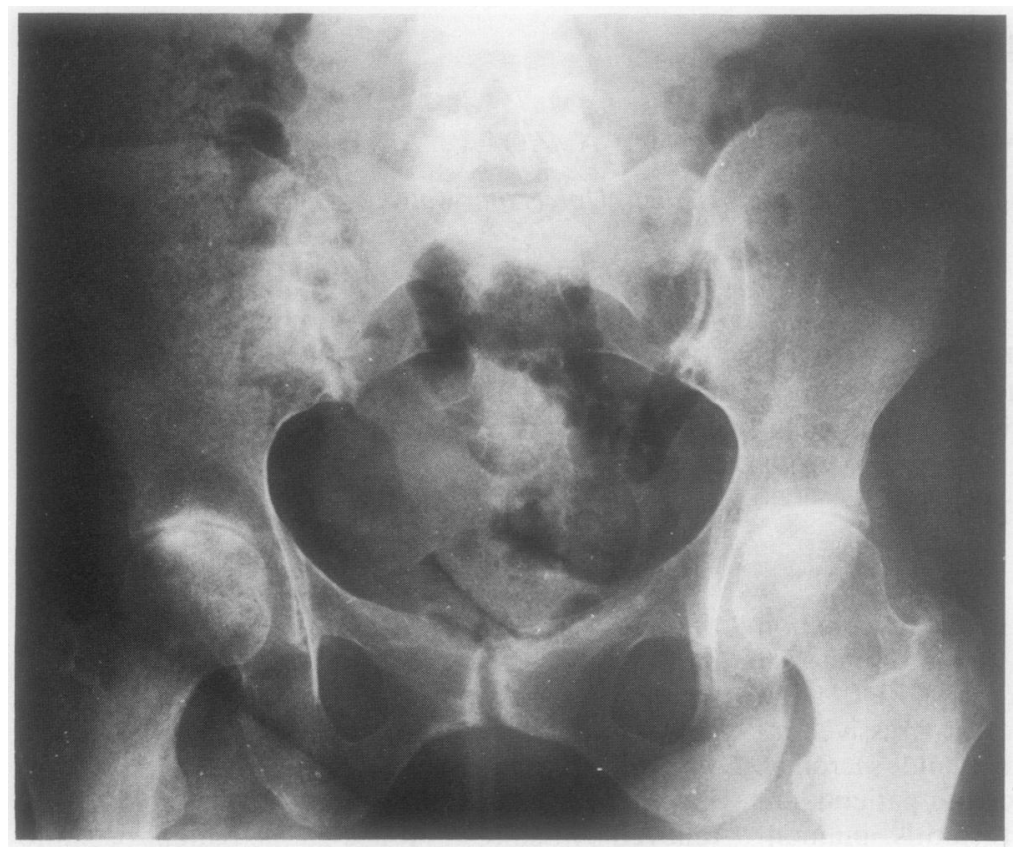

Fig. 1 Radiograph of the pelvis showing bilateral sacroiliitis.

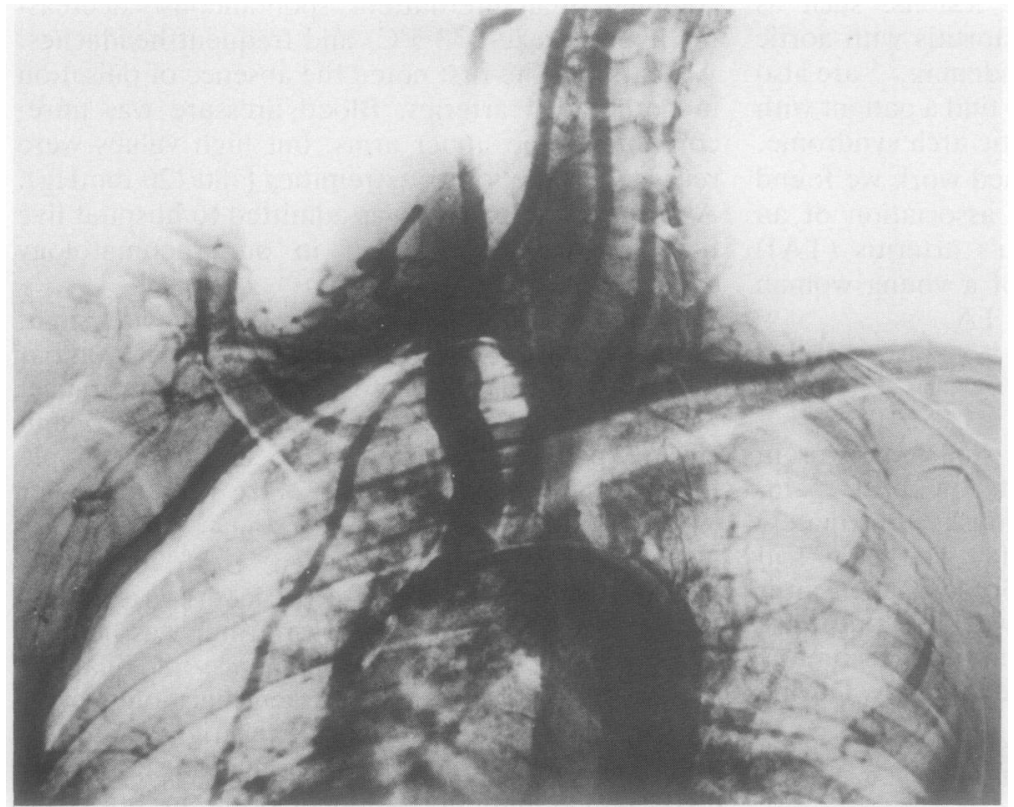

Fig. 2 Arch aortogram showing N occlusion of both subclavian arteries beyond the origin of the vertebral arteries. 
were negative. The patient was typed for HLA antigens and showed the presence of HLA-A2, Aw32, B27, Bw35, and Cw4.

Before reaching our department the patient had been treated with non-steroidal anti-inflammatory drugs and discontinuous steroid treatment in unascertainable doses.

\section{Discussion}

Reports of only seven cases of TA associated with AS have been published. It is not yet known whether this is a chance finding. In our patient both the diagnostic criteria for AS of Moll and Wright ${ }^{\prime \prime}$ and those for $\mathrm{TA}^{12}$ were met, confirming the diagnosis of both conditions. It is noteworthy that for TA the laboratory findings, angiographic studies, and clinical course (i.e., the loss of peripheral pulses in an adult) strongly support the evidence of an aortic arch syndrome as opposed to a congenital coarctation of the aorta. ${ }^{2-1+} \mathrm{A}$ temporal artery biopsy was performed to exclude the possibility of giant cell arteritis.

Our case supports previously published reports, which indicate a clear prevalence of women over men for this disease association (6:1 ratio). This sex preference is similar to that for TA compared with AS where there is a slightly higher prevalence in men. ${ }^{1}$

As in five of the six female cases previously reported ${ }^{7810}$ our patient's symptoms began before the age of 25. HLA tissue typing showed the presence of HLA-A2, Aw32, B27, Bw35, and Cw4. There was no evidence of HLA-Bw52, which Numano et al consider as the HLA type most strictly related to TA in all ethnic groups. ${ }^{15}$ We did not feel that HLA typing of the D locus would be helpful as there is still disagreement about the association between the $\mathrm{D}$ locus antigens and TA. ${ }^{15-17}$

Our case is the first in which the association of TA and AS is found in an HLA-B27 positive patient. This permits us to state that the above association can occur in both HLA-B27 negative $\mathrm{AS}^{8-10}$ and HLA-B27 positive AS.

It is not yet possible to identify a specific genetic marker common to the two disorders as the available data are extremely limited and incomplete. Therefore, we feel that future immunogenetic investigations on a wider scale are necessary.

The patient's case history and clinical findings lead us to believe that arteritis and arthritis have a simultaneous onset even though the spondarthritis had been diagnosed first in our patient as in the previously reported seven cases. In fact, all patients contacted the physician when their articular pain became apparent, that is when they were still in a pre-pulseless phase. This finding may indicate that the arteritis-arthritis association is not random. Consequently, we believe that there is a still unknown common factor which causes either AS alone, or TA alone, or an association of both, in subjects with different immunogenetic predetermination.

\section{References}

1 Calin A. Fries J F. The striking prevalence of ankylosing spondylitis in 'healthy' w27 positive males and females. A controlled study. $N$ Engl J Med 1975; 293: 835-9.

2 Brewerton D A. Caffrey M. Hart F D, James D C O, Nicholls A, Sturrock R D. Ankylosing spondylitis and HLA-27. Lancet 1973: i: 904-7.

3 Schlosstein L. Terasaki P I. Bluestone R. Pearson C N. High association of an HLA antigen. w27 with ankylosing spondylitis. N Engl J Med 1973: 288: 704-6.

4 Bergfeldt L. Edmag O. Rays J. HLA-B27 associated heart disease. Am J Med 1984: 74: 961-7.

5 Bulkley B H. Roberts W C. Ankylosing spondylitis and aortic regurgitation. Description of the characteristic cardiovascular lesion from study of eight necropsy patients. Circulation 1973: 18: $101+-27$.

6 Tucker C. Fowles R E. Calin A. Popp R L. Aortitis in ankylosing spondylitis: carly detection of aortic root abnormalities with two dimensional echocardiography. Am J Cardiol 1982: 49: 680-6.

7 Paloheimo J A. Julkunen H, Siltanen P. Kajander A. Takayasu's arteritis and ankylosing spondylitis. Acta Med Scand 1966; 179: 77-85.

8 Ghozlan R, Amor B, Debarre F. Association d'une maladie de Takayashu et d'une spondylarthrite ankylosante, un nouveau cas. Ann Med Interne (Paris) 1977; 128: 959-63.

9 Hull R G. Asherson R A. Rennic J A N. Ankylosing spondylitis and an aortic arch syndrẹme. Br Heart J 1984; 51: $663-5$.

10 Cowley M L. Hickling P. Wells I P. Marshall A J. Takayasu's disease and bilateral sacroiliitis. Clin Exp Rheumatol 1987: 5: 67-70.

11 Moll J M H. Wright V. New York clinical criteria for ankylosing spondylitis. Ann Rheum Dis 1973; 32: 354-63.

12 Hall S. Barr W. Lie J T. Stanson A W. Kazmier F J. Hunder G G. Takayasu arteritis. A study of 32 North American patients. Medicine (Baltimore) 1985: 64: 89-99.

13 Bonventre M V. Takayasu`s discase revisited. NY State J Med 1974; 74: 196()-7.

14 Chérigié E, Chermet J. Maladic de Takayashu. Aspects angiographiques habituels et inhabituels. A propos de 15 observations artériographiques. Journal de Radiologie, d'Electrologie et de Medecine Nucleaire 1975; 56: 21-33.

15 Numano F. Isohisa I. Egami M. Ohta N. Sasazuki T. HLA-DR MT and MB antigens in Takayasu disease. Tissue Antigens 1983: 21: 208-12.

16 Volkman D J, Mann D L. Fauci A S. Association between Takayasu's arteritis and B-cell alloantigen in North Amcricans. $N$ Engl J Med 1982; 306: 464-5.

17 Yokota A, Tanabe T, Yasuda K. Association of HLA-D region antigen with aortitis syndrome Takayasu's disease. Jpn Circ J 1981: 45: 893-5. 